\section{Adherence therapy for people with schizophrenia}

\author{
European multicentre randomised controlled trial \\ RICHARD GRAY, MORVEN LEESE, JONATHAN BINDMAN, THOMAS BECKER, \\ LORENZO BURTI, ANTHONY DAVID, KEVIN GOURNAY, MARTIJN KIKKERT, \\ MAARTEN KOETER, BERND PUSCHNER, AART SCHENE, \\ GRAHAM THORNICROFT and MICHELE TANSELLA
}

\author{
Background There is equivocal \\ evidence of the effectiveness of adherence \\ therapy in improving treatment adherence \\ and clinical outcomes for people with \\ schizophrenia.
}

\begin{abstract}
Aims To evaluate the effectiveness of adherence therapy in improving quality of life for people with schizophrenia.
\end{abstract}

Method A 52-week, single-blind, multicentre randomised controlled trial of the effectiveness of adherence therapy. Participants were individually randomised to receive eight sessions of adherence therapy or health education. Assessments were undertaken at baseline and at 52-week follow-up.

Results Adherence therapy was no more effective than health education in improving quality of life.

\section{Conclusions This effectiveness trial provides evidence for the lack of effect of adherence therapy in people with schizophrenia with recent clinical instability, treated in ordinary clinical settings.}

\section{Declaration of interest None.} Funding detailed in Acknowledgements.
It has been estimated that non-adherence rates for prescribed antipsychotic medications are about 50\% (Nose et al, 2003a). Relapse rates have been shown to be five times higher in people with schizophrenia who are non-adherent to medication compared with adherent people, resulting in a significant social and economic burden (Robinson et al, 1999).

Zygmunt et al (2002) reviewed randomised controlled trials of adherence interventions in schizophrenia. They showed that only one-third of these studies reported significant treatment effects, but that interventions based upon the principles of motivational interviewing were 'promising'. A subsequent meta-analysis concluded that psychiatric services could use effective clinical interventions for reducing patient non-adherence, but that the benefit of these interventions would be more evident in the short term than in the long term (Nose et al, 2003b). A recent randomised controlled trial of in-patients compared adherence therapy with non-specific counselling over 1 year, and found no clear advantage (O'Donnell et al, 2003).

\section{METHOD}

The main aim of this study was to compare the effectiveness of adherence therapy with a health education control intervention (which allows for therapist time and relationship), in improving health-related quality of life for people with schizophrenia receiving treatment from general adult mental health services in four European cities. The primary a priori hypothesis was that adherence therapy would result in improved quality of life for people with schizophrenia, compared with health education. Secondary a priori hypotheses were that, compared with health education, adherence therapy would improve medication adherence and symptoms.
The study design was a two-arm randomised controlled trial, with masking of assessors to the status of the participants. The interventions were delivered in routine general adult psychiatric settings, to maximise the generalisability of the results of this effectiveness trial (Tunis et al, 2003).

\section{Study participants}

Participants were recruited from June 2002 to October 2003 from people under the care of psychiatric services. A researcher approached senior treating clinicians at a range of locally typical general adult psychiatric in-patient and community settings, serving catchment areas in each of the four study sites: Amsterdam (The Netherlands), Leipzig (Germany), London (England) and Verona (Italy).

There were three inclusion criteria. First, a clinical diagnosis of schizophrenia should be confirmed by a research diagnosis of schizophrenia, established using the Item Group Checklist (IGC) of the Schedule for Clinical Assessment in Neuropsychiatry (SCAN; Wing et al, 1990) when applied to case notes, using International Classification of Disease criteria (ICD-10; World Health Organization, 1992). Second, patients should need continuing antipsychotic medication for at least the year following baseline assessment, in the judgement of the responsible treating senior psychiatrist. Third, there should be evidence of clinical instability in the year before baseline, defined by one or more of the following: at least one hospital admission on mental health grounds, a change in type or dose of antipsychotic medication, planned or actual increased frequency of contact with mental health services, and indications of clinical instability reported by relatives, carers or the clinical team.

Exclusion criteria were: presence of moderate or severe mental handicap (learning disability); organic brain disorders; current treatment by forensic psychiatric services; alcohol or drug dependence; inability to speak the language of host country to a sufficient standard to receive the intervention; or assessment by the treating clinician as lacking capacity to give valid consent to participate.

\section{Study procedures}

Individuals participated only if they gave written, informed consent. All study sites gained full approval for the study from 
the appropriate local research ethics committee (institutional review board). Once participants had given consent, they underwent baseline interviews and then received a unique identification number. This was sent to an independent clinical trials unit, where allocation was carried out by permuted blocks of random size, stratified by centre. The allocation was notified to the therapist, who arranged directly with the participant for the allocated treatment to be given. The researcher who conducted the baseline interview and the follow-up assessment remained masked to allocation throughout the study, to minimise bias. Participants were not masked to whether they were receiving adherence therapy or health education, and consequently this cannot be considered a double-blind trial. However, participants were informed that they would receive one of two interventions but were not told which was regarded by the investigators as the experimental intervention, and remained masked to the exact aims of the study.

\section{Study interventions}

The experimental intervention, adherence therapy, is a brief individual cognitivebehavioural approach (Kemp et al, 1996, 1998; Gray et al, 2004). The adherence therapy manual (http://www.adherencetherapy. com) describes a collaborative, patientcentred phased approach to promoting treatment adherence in people with schizophrenia. There are six elements that form the core of the therapy: assessment; medication problem-solving; a medication timeline; exploring ambivalence; discussing beliefs and concerns about medication; and using medication in the future. Key therapy skills that therapists use include exchanging information, developing discrepancy between the patient's thoughts and behaviours about medication, and working with resistance to discussing psychiatric medication and treatment. The aim of the therapy process is to achieve a joint decision about medication between the individual and therapist. A central tenet of the therapy is that where patients and therapists make choices about treatment together, adherence to that regimen will be enhanced.

Previous trials of adherence interventions have used a non-specific counselling intervention or standard care as the control intervention (Zygmunt et al, 2002). We offered participants a control intervention that would be acceptable and was not expected to enhance medication adherence, but which did control for the time spent with the therapist (Roth \& Fonagy, 1996). We chose didactic health education rather than standard care alone as the control condition, to control for therapist time and other non-specific aspects of the intervention. The eight individual sessions of the health education package included presentations on health education-related topics such as diet and healthy lifestyle. Therapists presented information in a didactic way, and were trained not to use any adherence therapy skills or techniques.

For both experimental and control conditions, participants were offered a maximum of eight weekly sessions of adherence therapy or health education, each lasting on average between 30 and $50 \mathrm{~min}$. Completion of treatment was defined as having attended at least five of the eight sessions over a maximum 5-month period. Both interventions were provided by one of nine therapists (four psychologists, three psychiatrists and two mental health nurses), all of whom had a background in delivering clinical interventions to people with schizophrenia. Treatment fidelity was assured as follows:

(a) Both adherence therapy and health education interventions were described in detail in manuals.

(b) The English language manuals were translated and back-translated into the appropriate languages (Dutch, German and Italian).

(c) All therapists met for 7 days to receive intensive training, using videomodelling and role-play rehearsal of key skills.

(d) Randomly selected therapy sessions (37) were audiotaped and independently rated using the Adherence Therapy Checklist (ATC; Vallis et al, 1986).

(e) Throughout the 18 months of the intervention period, therapists attended monthly group telephone clinical supervision, focusing on case presentations, the resolution of clinical problems, and adherence to therapy manuals.

Both adherence therapy and health education were offered at each site in addition to treatment-as-usual, which consisted of regular contact with psychiatrists and case managers, pharmacological therapy and the availability of day care, social support and acute hospital admission as required (Becker et al, 2002).

\section{Outcome measures}

Assessments took place at baseline and at 1 year after randomisation. The assessment scales included measures of sociodemographic characteristics, quality of life, adherence and psychopathology. The key results for the following scales are reported.

\section{Medical Outcome Study (MOS) 36-Item Short Form Health Survey (SF-36)}

The SF-36 is a self-report multidimensional survey measure of health-related quality of life and well-being (Ware \& Sherbourn, 1992). The scales of the SF-36 address eight health domains, and two summary measures are provided: a physical component summary score (PCS) and a mental component summary score (MCS). The MCS was selected as the main quality of life (QoL) outcome measure, as it has been shown to have good sensitivity to change, which is uncommon among QoL measures (Rood et al, 2000). Further, in people with severe mental illness, the SF-36 has been found to have well-established psychometric properties (test-retest reliability and internal consistency) (Russo et al, 1998; Tunis et al, 1999).

\section{Schedule for the Assessment of Insight - Expanded Version (SAI-E)}

From this semi-structured interview, we used the keyworker rating of adherence, referred to as the SAI-C, on a scale ranging from 1 (complete refusal) to 7 (active participation in treatment) (David, 1990).

\section{Medication Adherence Questionnaire (MAQ)}

The MAQ addresses how patients may fail to take their medication as prescribed, for example because of forgetfulness, carelessness, stopping the drug when they feel better, or stopping the drug because they believe it makes them feel worse. The scale has good levels of validity and reliability (Morisky et al, 1986).

\section{Brief Psychiatric Rating Scale - Expanded (BPRS-E)}

The BPRS-E consists of 24 items measuring psychiatric symptoms (Lukoff et al, 1986; Ventura et al, 1993). It measures four different dimensions: positive symptoms, 
negative symptoms, depression and anxiety and manic excitement or disorganisation.

\section{Sample size}

A sample size of 300 participants was sought (150 in the treatment and 150 in the control group). This was sufficient to detect an overall difference between intervention and control of six points in the SF-36 MCS scale, based upon previous studies using such a magnitude of clinical change (Ware \& Kosinski, 2003a) and equivalent to a medium standard effect size, with over $99 \%$ power. The calculation assumes that the analysis would adjust for baseline values, that the pre-post correlation would be 0.5 , and a standard deviation of the MCS of about 12, as found in MOS patients (adults in various settings with depression in the USA) (Ware \& Kosinski, $2003 b$ ). With an estimated $25 \%$ attrition rate, this required the recruitment of 400 participants (100 per site on average) at baseline.

\section{Statistical methods}

The effect of the intervention on the outcomes was assessed by comparing the mean values for intervention and control at follow-up using analysis of covariance (Mickey et al, 2004) to control for baseline value and site. The analyses were completed on an intention-to-treat basis. Double-sided critical levels for significance tests were used. Pro-rating dealt with missing items in the computation of sub-scales for each participant, so long as there were fewer than $20 \%$ missing items for that person; otherwise, the scale was set to missing. This rule was overridden where there were specific instructions for the scale (as in the case of the SF-36). If participants had an observation at neither time point, they were excluded. Where only one value was present, imputation was used for sensitivity analyses but not in results tables or primary analyses. Mean (within-site) imputation was involved for missing continuous covariates at baseline, such as the baseline values of the outcomes, and analyses were weighted if necessary (White \& Thompson, 2005). Follow-up values were also imputed from baseline values, and any other relevant variables at follow-up, if available. As a further sensitivity analysis, the MAQ and SAI-C scales, which were short scales with non-normally distributed data, were analysed using ordered logistic regression. Microsoft Access databases and SPSS version 11 for Windows were used for initial data acquisition and checking, and Stata version 8.2 for the analyses.

\section{RESULTS}

\section{Socio-demographic characteristics}

The randomisation produced no substantial differences between the control and treatment groups at baseline (Table 1). As is common in treated prevalence studies of schizophrenia, the mean age of the sample was in the early forties, the slight majority were male, and relatively few were married or cohabiting. Three-quarters of the participants were White, and almost half lived alone, usually in owned or rented accommodation; only about $15 \%$ were in paid employment.

\section{Clinical characteristics}

At baseline there were no substantial clinical differences between the control and treatment groups (Table 1). Participants in both groups had spent about 1 month in the year before baseline as in-patients, and had been treated with antipsychotic medication for about 12 years. Between sites there were some differences in the profiles of symptoms and disability, but the variations in patterns of service use were more marked and reflected different service configurations in each of the four areas studied (Table 2) (Chisholm \& Knapp, 2002).

\section{Participant flow}

Figure 1 shows the flow of participants through the study in the CONSORT format. Of the 1218 people screened, 917 were eligible to participate in the study. Of these, $366(39.9 \%)$ refused to participate, $142(15.5 \%)$ could not be randomised for other reasons, so a total of 409 (44.6\%) were randomised. The three most common reasons for refusing to participate in the study were that potential participants did not have enough time, were not interested in the study or did not want to participate in research.

\section{Study completion and attribution rates}

Baseline and follow-up data for the core outcome measures were collected for 349 $(85.3 \%)$ participants: $184(90 \%)$ in the health education group and $165(81 \%)$ in the adherence therapy group, a difference in follow-up rate that was statistically significant $(P=0.01)$. Table 3 shows that,

Table I Socio-demographic and clinical characteristics of the sample at baseline

\begin{tabular}{|c|c|c|c|}
\hline Characteristic & $\begin{array}{c}\text { Adherence } \\
\text { therapy } \\
n=204\end{array}$ & $\begin{array}{c}\text { Health } \\
\text { education } \\
n=205\end{array}$ & $\begin{array}{l}\text { Overall } \\
n=409\end{array}$ \\
\hline Age, years: mean (s.d.) & $40.9(11.7)$ & $42.1(11.4)$ & $4 I .5(11.5)$ \\
\hline Male, $n(\%)$ & $122(60)$ & $123(60)$ & $245(60)$ \\
\hline Married or cohabiting, $n(\%)$ & $25(12)$ & $22(I I)$ & $47(11.5)$ \\
\hline White European, $n$ (\%) & $|5|(74)$ & $159(78)$ & $310(76)$ \\
\hline Primary/secondary education only, $n$ (\%) & $136(67)$ & $135(67)$ & $271(67)$ \\
\hline Living alone, $n(\%)$ & $84(4 I)$ & $81(40)$ & $165(40)$ \\
\hline Living with partner, $n$ (\%) & $31(53)$ & $28(48)$ & $59(14.5)$ \\
\hline Living with family, $n(\%)$ & $45(49)$ & $47(5 \mathrm{I})$ & $92(22.5)$ \\
\hline Living with others (e.g. hostel), n (\%) & $43(47)$ & $49(53)$ & $92(22.5)$ \\
\hline Accommodation: owned or rented, $n(\%)$ & $155(76)$ & $159(78)$ & $314(77)$ \\
\hline Employment: paid or self-employed, $n$ (\%) & $29(14)$ & $30(15)$ & $59(14.5)$ \\
\hline Psychiatric in-patient days in past year, mean (s.d.) & $28.1(57.4)$ & $27.8(63.4)$ & $27.9(60.4)$ \\
\hline Any psychiatric admission in past year, $n(\%)$ & $82(40)$ & $77(38)$ & $159(39)$ \\
\hline $\begin{array}{l}\text { Years from first antipsychotic treatment to } \\
\text { interview, mean (s.d.) }\end{array}$ & $13.0(9.4)$ & $14.3(10.3)$ & $13.6(9.9)$ \\
\hline MAQ total score, mean (s.d.) & $2.96(1.25)$ & $2.98(1.19)$ & $2.97(1.21)$ \\
\hline BPRS-E total score, mean (s.d.) & $46.1(13.4)$ & $44.3(12.5)$ & $45.2(13.0)$ \\
\hline SF-36 MCS, mean (s.d.) & $38.4(I I .2)$ & $40.1(12.1)$ & 39.2 (11.7) \\
\hline
\end{tabular}

MAQ, Medical Adherence Questionnaire; BPRS, Brief Psychiatric Rating Scale; MCS, mental component summary of Medical Outcome Study SF-36. 
Table 2 Key baseline characteristics of participants, compared by site'

\begin{tabular}{lccccc}
\hline Characteristic & \multicolumn{5}{c}{ Site } \\
\cline { 2 - 6 } & Amsterdam & Leipzig & London & Verona \\
\hline Age, years: mean (s.d.) & $40.0(10.2)$ & $38.70(10.7)$ & $42.52(11.7)$ & $44.29(12.36)$ \\
Years of medication, mean (s.d.) & $12.7(9.2)$ & 11.6 & $(8.7)$ & $15.8(11.4)$ & $14.3(9.7)$ \\
In-patient days in past year, mean (s.d.) & $46.3(90.7)$ & $48.8(59.1)$ & $17.5(43.5)$ & $3.7(9.7)$ \\
BPRS score, mean (s.d.) & $37.5(10.2)$ & $48.3(15.7)$ & $46.0(11.1)$ & $48.3(11.5)$ \\
Male, $n$ (\%) & $73(73)$ & $55(57)$ & $50(54)$ & $67(56)$ \\
White European, $n$ (\%) & $44(44)$ & $97(100)$ & $49(53)$ & $120(100)$ \\
Any psychiatric admission in past year, & $40(40)$ & $72(74)$ & $24(26)$ & $23(19)$ \\
$n$ (\%) & & & & \\
\hline
\end{tabular}

BPRS, Brief Psychiatric Rating Scale.

I. $n=366$ for years of medication; for other variables, $n=406-409$.

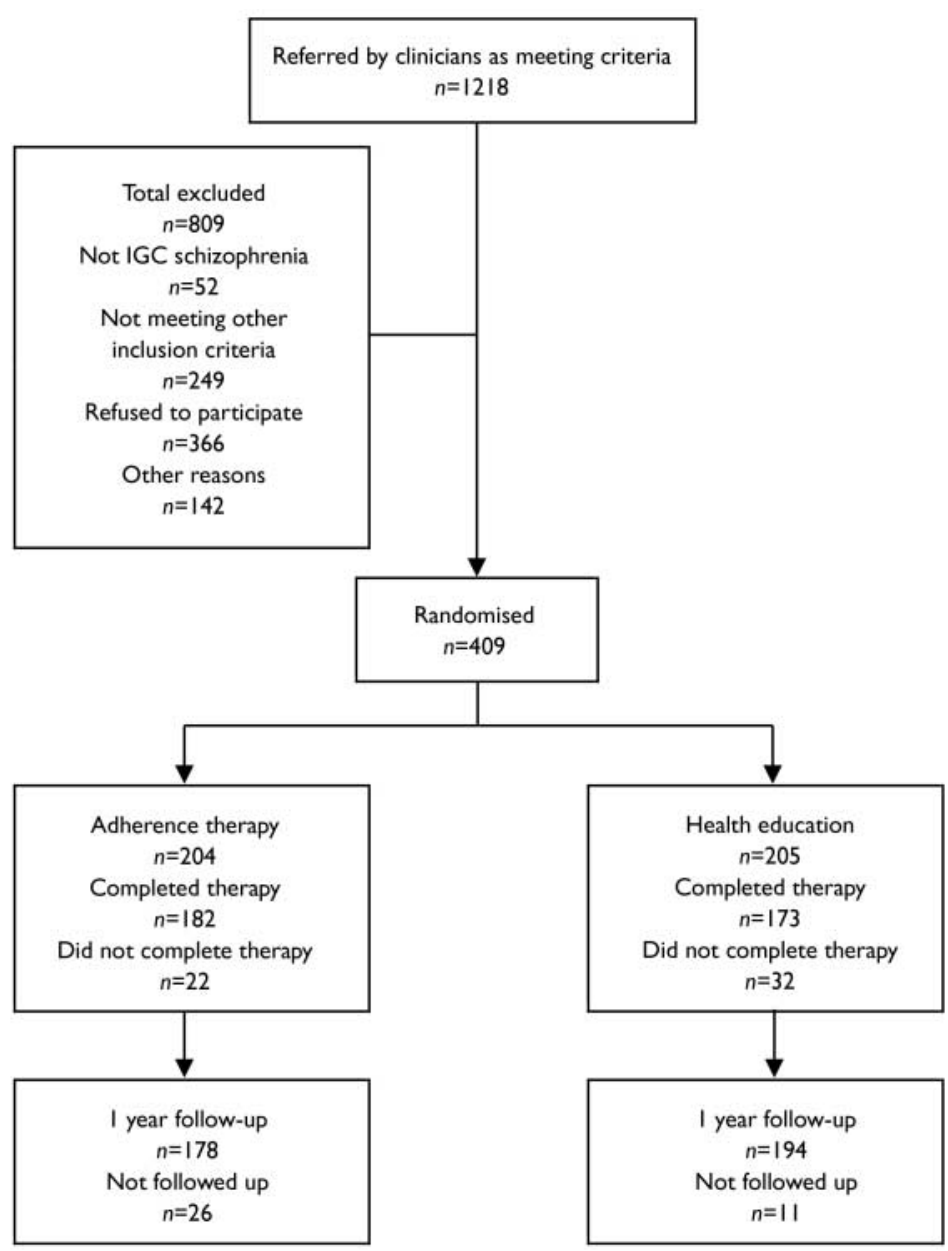

Fig. I CONSORT diagram. ICG, Item Group Checklist of the Schedule for Clinical Assessment in Neuropsychiatry

overall, people who dropped out of the trial tended to have had more in-patient days $(P=0.022)$, but in other respects were similar to those who completed the interviews, and the drop-outs were similar in the two arms.

\section{Uptake of interventions and fidelity}

The mean number of sessions of adherence therapy was 7 (s.d.=1.96) and the mean duration of each session was $36 \mathrm{~min}$

(s.d.=12.10). The mean number of sessions of health education was 7 (s.d.=2.49) and the mean duration of each session was $30 \mathrm{~min}$ (s.d.=9.92). In all, 54 participants did not complete treatment (attended fewer than 5 sessions in a 5 month period), split evenly between the two groups.

Independent evaluation of 20 audiotapes of health education and 17 of adherence therapy, using the ATC, revealed that the adherence therapy was delivered in a way that was highly consistent with the adherence therapy manual. Participants receiving health education did not receive any of elements of adherence therapy.

\section{Outcomes of intervention}

\section{Quality of life}

There were no significant differences in quality of life between the two intervention groups at baseline or at follow-up (Table 4). Sensitivity analyses confirmed this finding.

\section{Medication adherence}

There was no significant difference between adherence therapy and health education at follow-up. This indicates that interventions were essentially equivalent. Sensitivity analyses did not reveal any major difference in these findings.

We conducted an exploratory post-hoc analysis to examine the effect of adherence therapy in a subgroup of the less treatmentadherent participants (defined as a score of 2 or lower on the MAQ). Although such an analysis was not planned a priori, it was considered informative to explore any possible effect of adherence therapy in a sample of non-adherent individuals. Just under a third of the sample $(n=120,30 \%)$ met this criterion. There was no significant difference in medication adherence between the groups at follow-up.

\section{Psychopathology}

The experimental and control groups did not differ significantly at baseline or at follow-up in terms of psychopathology.

\section{DISCUSSION}

This study showed that adherence therapy had no clear benefit in terms of treatment adherence, psychopathology or quality of life when compared with health education, 
Table 3 Comparison of participant trial completers and drop-outs and those lost to follow-up (baseline scores)

\begin{tabular}{|c|c|c|c|c|}
\hline \multirow[t]{2}{*}{ Characteristic } & \multicolumn{2}{|c|}{ Adherence therapy } & \multicolumn{2}{|c|}{ Health education } \\
\hline & Completers & Non-completers & Completers & Non-completers \\
\hline Age, years: mean (s.d.) & $42.1($ (II.2) & $41.9(13.9)$ & $4 I .0(I I .7)$ & $40.4($ (II.5) \\
\hline Male, $n(\%)$ & $105(60)$ & $8(62)$ & $115(60)$ & $17(59)$ \\
\hline Married/cohabiting, $n$ (\%) & $20(10)$ & $2(15)$ & $24(14)$ & I (3) \\
\hline White European, $n$ (\%) & $149(78)$ & $10(77)$ & $130(74)$ & $21(72)$ \\
\hline $\begin{array}{l}\text { No education beyond secondary } \\
\text { level, } n(\%)\end{array}$ & $126(66)$ & $9(69)$ & $116(67)$ & $21(72)$ \\
\hline Living alone, $n$ (\%) & $79(4 I)$ & $2(15)$ & $70(40)$ & $14(48)$ \\
\hline $\begin{array}{l}\text { Psychiatric in-patient days } \\
\text { in past year, mean (s.d.) }\end{array}$ & $26.9(62.5)$ & $4 I .2(77.1)$ & $24.2(54.8)$ & $51.2(67.5)$ \\
\hline MAQ total score, mean (s.d.) & $2.96(1.20)$ & $3.23(1.01)$ & $2.97(1.25)$ & $2.93(1.27)$ \\
\hline BPRS total score, mean (s.d.) & $44.3(12.8)$ & $44.3(12.6)$ & $45.9(13.2)$ & $47.0(14.7)$ \\
\hline SF-36 MCS, mean (s.d.) & $40.1(12.2)$ & $40.0(10.9)$ & $38.3(10.9)$ & $38.7(13.3)$ \\
\hline
\end{tabular}

MAQ, Medical Adherence Questionnaire; BPRS, Brief Psychiatric Rating Scale; MCS, mental component summary of medical outcome study SF-36.

for people with generally chronic schizophrenia, in general adult mental health services, who showed recent clinical instability.

The study is the largest trial of adherence therapy to be conducted to date, and the sample size allows adequate statistical power to give a clear answer to the research question. High levels of treatment fidelity were achieved for both interventions. The intervention and control interventions were delivered by trained and clinically experienced therapists, and given over an average of seven sessions each which was realistic clinically (Kemp et al, 1998; O'Donnell et al, 2003). The SF-36 MCS is a well-established measure of direct clinical relevance, which has been used in studies of people with schizophrenia (Meijer et al, 2002). Research ratings were conducted in a masked fashion, and high rates of follow-up were achieved.

We shall discuss the interpretation of our findings in terms of the patients referred to and included in the trial, the intervention, the therapists and the timing of assessments.

Over two-thirds of the patients referred to this trial as meeting the inclusion criteria were excluded and not randomised. Almost a third of the patients referred to the study refused to participate, and a further 142 were excluded for other reasons (e.g. they initially agreed to participate and then withdrew, or the research worker was unable to make contact with them). It is possible that this may have biased our sample towards a subsample of more cooperative and adherent people who were unlikely to benefit from adherence therapy.

The sample selection meant that we recruited people who, despite the inclusion criterion of evidence of clinical instability in the previous year, had levels of selfreported treatment adherence which were only moderately impaired (Breen \& Thornhill, 1998; Lacro et al, 2002; Nose et al, 2003b). It is therefore possible that a ceiling effect was operating, in which there was little room for further adherence improvement. The subgroup analysis of participants with low treatment adherence, however, suggests there was no beneficial effect of adherence therapy even for the least adherent individuals, compared with health education. In addition, there were low rates of agreement between patientrated and staff-rated scores of treatment

Table 4 Outcomes measures at baseline and follow-up according to treatment group

\begin{tabular}{|c|c|c|c|c|c|c|c|c|c|c|}
\hline \multirow[t]{2}{*}{ Measure } & \multicolumn{3}{|c|}{ Adherence therapy } & \multicolumn{3}{|c|}{ Health education } & \multicolumn{2}{|c|}{$\begin{array}{c}\text { Difference' at follow-up } \\
\text { (all available cases) }\end{array}$} & \multicolumn{2}{|c|}{$\begin{array}{c}\text { Difference' at follow-up } \\
\text { (complete cases) })^{2}\end{array}$} \\
\hline & $n$ & $\begin{array}{c}\text { Baseline } \\
\text { mean score } \\
\text { (s.d.) }\end{array}$ & $\begin{array}{l}\text { Follow-up } \\
\text { mean score } \\
\text { (s.d.) }\end{array}$ & $n$ & $\begin{array}{c}\text { Baseline } \\
\text { mean score } \\
\text { (s.d.) }\end{array}$ & $\begin{array}{l}\text { Follow-up } \\
\text { mean score } \\
\text { (s.d.) }\end{array}$ & Difference & $P$ & Difference & $P$ \\
\hline $\begin{array}{l}\text { Quality of life } \\
\text { (SF-36 MCS) }\end{array}$ & 175 & 38.34 (10.89) & $40.24(11.97)$ & 192 & $40.12(12.25)$ & 41.32 (II.49) & $\begin{array}{c}-1.08 \\
(-3.49 \text { to } 1.33)\end{array}$ & 0.38 & $\begin{array}{c}-0.40 \\
(-2.56 \text { to } 1.76)\end{array}$ & 0.72 \\
\hline Adherence $(\mathrm{MAQ})^{3}$ & 172 & $2.98(1.24)$ & $3.20(1.07)$ & 194 & $2.97(1.20)$ & $3.33(1.02)$ & $\begin{array}{c}-0.13 \\
(-0.35 \text { to } 0.08)\end{array}$ & 0.23 & $\begin{array}{c}-0.15 \\
(-0.34 \text { to } 0.05)\end{array}$ & 0.15 \\
\hline Adherence $(\mathrm{SAI}-\mathrm{C})^{4}$ & 173 & $5.04(1.39)$ & $5.22(1.57)$ & 189 & $4.73(1.63)$ & $5.03(1.55)$ & $\begin{array}{c}0.19 \\
(-0.12 \text { to } 0.52)\end{array}$ & 0.24 & $\begin{array}{c}-0.16 \\
(-0.32 \text { to } 0.29)\end{array}$ & 0.92 \\
\hline Symptoms (BPRS) & 175 & $45.96(13.23)$ & 38.11 (II.33) & 196 & 44.31 (12.79) & 37.34 (9.79) & $\begin{array}{c}0.77 \\
\text { (- I.39 to } 2.93)\end{array}$ & 0.48 & $\begin{array}{c}0.13 \\
(-1.84 \text { to } 2.09)\end{array}$ & 0.90 \\
\hline
\end{tabular}

MCS, mental component summary of Medical Outcome Study; MAQ, Medication Adherence Questionnaire; SAl-C, Schedule for the Assessment of Insight - Compliance item; BPRS, Brief Psychiatric Rating Scale.

I. Difference between adherence therapy and health education groups.

2. Adjusted for site and baseline level.

3. Range is $0-4$, higher scores indicating greater treatment adherence.

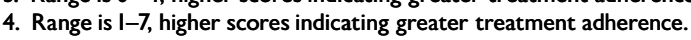


adherence. This confirms previous views that non-invasive measures of treatment adherence are poorly validated, whereas studies using biological assays, such as hair, urine or blood specimens, may be more valid. However, the latter raise their own problems such as low rates of consent among poorly treatment-adherent patients, and may themselves intervene to change adherence for as long as they take place (Cummings et al, 1984; Matsui et al, 1994; World Health Organization, 2003).

The interventions were offered in a single course of therapy over 5 months or less, with no booster sessions. Although the number of hours of intervention offered was as much as most services in these countries could implement routinely, it is possible that this was an insufficient dose of treatment to be effective, although our data do not suggest even a modest treatment effect of adherence therapy compared with health education as delivered. Effectiveness might have been reduced by the use of therapists not previously known to the participant. This approach is clinically realistic, as it is usual in service studies for structured psychological interventions to be given by therapists not previously known to the patient.

The study extends previous work in this field in several respects. The results are applicable to patients with schizophrenia in a range of general adult treatment settings, rather than the in-patient samples used in previous studies (Kemp et al, 1998; O’Donnell et al, 2003). The results were consistent across all four study sites in different countries, despite some marked differences in patterns of service provision. Our results challenge the conclusions of previous reviews (Zygmunt et al, 2002; Nose et al, 2003a), which have indicated that such forms of adherence therapy show therapeutic promise. Our study also generates hypotheses for future studies, for example that adherence therapy might be effective when delivered by staff who are already members of a multidisciplinary clinical team, or that it might be selectively effective only in those patients who are least treatment adherent. This study therefore provides evidence of a lack of effect for adherence therapy in improving treatment adherence, psychopathology or quality of life of people with schizophrenia. The important challenge of how best to assist people with schizophrenia, who are unwilling or unable to adhere to

RICHARD GRAY, RN, PhD, MORVEN LEESE, PhD, JONATHAN BINDMAN, MRCPsych, PhD, Health Services Research Department, Institute of Psychiatry, King's College London, UK; THOMAS BECKER, MD, Department of Psychiatry II, University of Ulm, BKH Günzburg, Germany; LORENZO BURTI, MD, Department of Medicine and Public Health, Policlinico G.B. Rossi, Verona, Italy; ANTHONY DAVID, FRCPsych, MD, Section of Cognitive Neuropsychiatry; KEVIN GOURNAY, RN, PhD, Health Services Research Department, Institute of Psychiatry, King's College London, UK; MARTIJN KIKKERT, MSc, MAARTEN KOETER, PhD, Academic Medical Center, Department of Psychiatry, University of Amsterdam, The Netherlands; BERND PUSCHNER, PhD, Department of Psychiatry II, University of Ulm, BKH Günzburg, Germany; AART SCHENE, MD, PhD, Academic Medical Center, Department of Psychiatry, University of Amsterdam, The Netherlands; GRAHAM THORNICROFT, FRCPsych, PhD, Health Services Research Department, Institute of Psychiatry, King's College London, UK; MICHELE TANSELLA, MD, Department of Medicine and Public Health, Section of Psychiatry and Clinical Psychology, University of Verona, Italy.

Correspondence: Dr Richard Gray, Health Services Department, Institute of Psychiatry, King's College London, De Crespigny Park, London SE5 8AF, UK. Tel.: +44 (0)20 7848 0139; fax: +44 (0)20 7848 0458; email: R.Gray@iop.kcl.ac.uk

(First received I5 November 2005, final revision 29 June 2006, accepted I August 2006)

treatment recommendations, therefore remains unresolved.

\section{ACKNOWLEDGEMENTS}

We acknowledge the contributions of the patients, carers and staff who have taken part in the study. The study was funded by a grant from the Quality of Life and Management of Living Resources Programme of the European Union (QLG4-CT2001-01734).

\section{REFERENCES}

Becker, T., Hulsmann, S., Knudsen, H. C., et al (2002) Provision of services for people with schizophrenia in five European regions. Social Psychiatry and Psychiatric Epidemiology, 37, 465-474.

Breen, R. \& Thornhill, J.T. (1998) Noncompliance with medication for psychiatric disorders. Reasons and remedies. CNS Drugs, 9, 457-47I.

Chisholm, D. \& Knapp, M. (2002) The economics of schizophrenia care in Europe: the EPSILON study. Epidemiologia e Psichiatrica Sociale, II, 12-17.

Cummings, K. M., Kirscht, J. P., Becker, M. H., et al (1984) Construct validity comparisons of three methods for measuring patient compliance. Health Services Research 19, 103-116.

David, A. S. (1990) Insight and psychosis. British Journa of Psychiatry, 156, 798-808.

Gray, R., Wykes, T., Edmonds, M., et al (2004) Effect of a medication management training package for nurses on clinical outcomes for patients with schizophrenia: cluster randomised controlled trial. British Journal of Psychiatry, 185, 157-162.

Kemp, R., David, A. \& Hayward, P. (1996) Compliance therapy: an intervention targeting insight and treatment adherence in psychotic patients. Behavioural and Cognitive Psychotherapy, 24, 33I-350.

\section{Kemp, R., Kirov, G., Everitt, B., et al (1998)}

Randomised controlled trial of compliance therapy. 18-month follow-up. British Journal of Psychiatry, 172. $413-419$.

Lacro, J. P., Dunn, L. B., Dolder, C. R., et al (2002)

Prevalence of and risk factors for medication

nonadherence in patients with schizophrenia: a comprehensive review of recent literature. Journal of Clinical Psychiatry, 63, 892-909.

Lukoff, D., Liberman, R. P. \& Neuchterlein, K. H. (1986) Symptom monitoring in the rehabilitation of schizophrenic patients. Schizophrenia Bulletin, I2, 578-602.

Matsui, D., Hermann, C., Klein, J., et al (1994) Critical comparison of novel and existing methods of compliance assessment during a clinical trial of an oral iron chelator. Journal of Clinical Pharmacology, 34, 944-949.

Meijer, C. J., Schene, A. H. \& Koeter, M. W. J. (2002) Quality of life in schizophrenia measured by the MOS SF-36 and the Lancashire Quality of Life Profile: a comparison. Acta Psychiatrica Scandinavica, 105 293-300.

Mickey, R. M., Dunn, O. J. \& Clark, V. A. (2004) Applied Statistics: Analysis of Variance and Regression, 3rd edn. New York: John Wiley.

Morisky, D. E., Green, L.W. \& Levine, D. M. (1986) Concurrent and predictive validity of a self-reported measure of medication adherence. Medical Care, 24, 67-74.

Nosé, M., Barbui, C. \& Tansella, M. (2003a) How often do patients with psychosis fail to adhere to treatment programmes? A systematic review. Psychological Medicine, 33, II49-1160.

Nosé, M., Barbui, C., Gray, R., et al (2003b) Clinica interventions for treatment non-adherence in psychosis: meta-analysis. British Journal of Psychiatry, 183, 197-206.

O'Donnell, C., Donohoe, G., Sharkey, L., et al (2003) Compliance therapy: a randomised controlled trial in schizophrenia. BMJ, 327, 834

Robinson, D., Woerner, M. G., Alvir, J. M., et al (1999) Predictors of relapse following response from a first episode of schizophrenia or schizoaffective disorder. Archives of General Psychiatry, 56, 24I-247.

Rood, M. J., Borggreve, S. E. \& Huizinga,T.W. (2000) Sensitivity to change of the MOS SF-36 quality of life assessment questionnaire in patients with systemic lupus erythematosus taking immunosuppressive therapy. Journal of Rheumatology, 27, 2057-2059.

Roth, A. \& Fonagy, P. (1996) What Works for Whom? A Critical Review of Psychotherapy Research. New York: Guilford Press.

Russo, J., Trujillo, C. A., Wingerson, D., et al (1998) The MOS 36-Item Short Form Health Survey: 
reliability, validity, and preliminary findings in

schizophrenic outpatients. Medical Care, 36, 752-756.

Tunis, S. L., Croghan, T.W., Heilman, D. K., et a

(1999) Reliability, validity, and application of the medica outcomes study 36 -item short-form health survey (SF-36) in schizophrenic patients treated with olanzapine versus haloperidol. Medical Care, 37, 678-691.

\section{Tunis, S. R., Stryer, D. B. \& Clancy, C. M. (2003)}

Practical clinical trials: increasing the value of clinical research for decision making in clinical and health policy Journal of the American Medical Assocation, 290, 1624-1632.

Vallis, T. M., Shaw, B. F. \& Donson, K. S. (1986) The cognitive therapy scale: psychometric properties. Journa of Consulting and Clinical Psychology, 54, 38I-385.
Ventura, J., Green, M., Schaner, A., et al (1993) Training and quality assurance with the Brief Psychiatric Rating Scale. The 'drift busters'. International Journal of Methods in Psychiatric Research, 3, 221-244.

Ware, J. \& Sherbourn, C. (1992) The MOS, 36 item Short-Form Health Survey (SF-36). I. Conceptual framework and item selection. Medical Care, 30, 473-483.

Ware, J. E. \& Kosinski, M. (2003a) Physical and Mental Health Summary Scales. A Manual for Users of Version I, 2nd edn. Lincoln, RI: QualityMetric.

Ware, J. E. \& Kosinski, M. (2003b) SF-36 Physical and Mental Health Summary Scales. A Manual for Users of Version I, 2nd edn. Lincoln, RI: QualityMetric.
White, I. \& Thompson, S. (2005) Adjusting for partially missing baseline measurements in randomised trials. Statistics in Medicine, 24, 993-1007.

Wing, J. K., Babor, T., Brugha, T., et al (1990) SCAN Schedules for Clinical Assessment in Neuropsychiatry. Archives of General Psychiatry, 47, 589-593.

World Health Organization (1992) Tenth Revision of the International Classification of Diseases and Related Health Problems (ICD-10). Geneva: WHO.

World Health Organization (2003) Adherence to LongTerm Therapies: Evidence for Action. Geneva: WHO.

Zygmunt, A., Olfson, M., Boyer, C. A., et al (2002) Interventions to improve medication adherence in schizophrenia. American Journal of Psychiatry, 159. 1653-1664. 